\title{
A Smart RFID Device for Drugs Administration
}

\section{Ernesto ladanza*}

Department of Electronics and Telecommunications, Firenze, Italy

\begin{abstract}
In this work a device is described that can be used in hospitals to lower the risk of Adverse Drug Events (ADE) due to the incorrect link between patients and drugs. The device is a container that can be handled by the patient himself of by the caregivers. It is provided with an internal lock that prevents any openings when there is a mismatch between the patient and the drugs inside the container. It is based on passive RFID (Radio Frequency Identification) technology and is designed to give a visual alert if a wrong drug (tagged with RFID) is accidentally inserted, also preventing its administration by locking the top aperture.
\end{abstract}

The internal RFID reader is designed to read both the patient's wristband and the drugs inserted into the device (provided that they are tagged with RFID): the device will not open if some un-prescribed drug is found inside the container, alerting the patient/operator using the on-board display.

Every single event is logged in an internal memory and can be transferred to a remote information system for analyses, statistics and risk management.

The device is also provided with two status LEDs, a green one and a red one, and with a text display that can show information about the patient's identity, and therapy.

We are now working on the mechanical design and on the development of management software in order to link the device with CPOE (Computerized Physician Order Entry) systems and with automated drug storage systems.

Keywords: RFID; Drugs administration; Patient safety; Patient's identification

\section{Introduction}

In this paper we will show the design of a device that is intended as a solution for reducing the number of Adverse Drug Events (ADEs) related to drugs administration to patients. The device is a container that incorporates an RFID (Radio Frequency Identification) reader in order to perform a check on patient's identity and to allow the administration of medications only to the right patient.

Many studies can be found in literature on this subject, assessing the problem of human factors in medication administration errors. Part of them are based on data coming from incident-reporting, others apply proactive analysis tools such as FMEA (Failure Modes and Effects Analysis) or HTA (Hierarchical Task Analysis). The National Coordinating Council for Medication Error Reporting and Prevention defines a medication error as "any preventable event that may cause or lead to inappropriate medication use or patient harm while the medication is in the control of the health care professional, patient, or consumer. Such events may be related to professional practice, health care products, procedures, and systems, including prescribing; order communication; product labelling, packaging, and nomenclature; compounding; dispensing; distribution; administration; education; monitoring; and use."[1] Adverse Drug Events (ADEs) are defined as injuries resulting from the use of a drug. Under this definition, ADEs include damages caused by the drug (adverse drug reactions and overdoses) and damages from the use of the drug (including dose reductions and discontinuations of medication therapy) [2].

According to $[3,4]$, the $28 \%$ of all the ADEs come from the medication administration step.

Technological solutions, such as radio frequency tagging has been widely suggested as a solution to the problem of the wrong identification of patients and of the incorrect association between patient and medications.

In this work we are focusing on the error in the administration step, defined as the change between what the physician's prescription and the actual medication administered to the patient. Medication errors that originate from mistakes during prescribing can be significantly reduced by using CPOE (Computerized Physician Order Entry) software, thereby solving problems related to incomplete orders, bad calligraphy, misunderstandings in abbreviations, incompatible drugs etc. Nevertheless, CPOE use itself cannot prevent that the medication that is actually given to the patient is different from what the doctor prescribed. We can notice a lack in patient's safety in the last step of the whole therapeutic process: the administration step.

Some authors claim that use of Barcode Point-of-Care Technology (BPOC) to reduce medication errors is a patient-safety approach that hospitals can implement within a short time frame and obtain immediate benefits [5]. Some claim that the integration of bar codes and radio frequency identification tags are viewed as critical in achieving effective and safe patient care although systems using these capabilities must be carefully planned to achieve optimal outcomes [6-8]

\section{Materials and Methods}

We propose a custom device based on passive RFID (Radio

*Corresponding author: Ernesto ladanza, Department of Electronics and Telecommunications, Firenze, Italy, E-mail: ernesto.iadanza@poste.it

Received March 19, 2012; Accepted April 18, 2012; Published April 20, 2012

Citation: ladanza E (2012) A Smart RFID Device for Drugs Administration. Pharm Anal Acta S15. doi:10.4172/2153-2435.S15-004

Copyright: (C) 2012 ladanza E. This is an open-access article distributed unde the terms of the Creative Commons Attribution License, which permits unrestricted use, distribution, and reproduction in any medium, provided the original author and source are credited. 
Frequency Identification) technology, able to check the correct relation between patient and drug containers and to trace every step of the drugs administration process.

Many different technologies are gathered under the acronym RFID, each optimized for some particular tasks. Factories can take advantage of RFID for managing and optimizing their supply-chains, inspecting the content of a pack without actually opening it. Stores use RFID as a substitute to barcode labels because it works even without any lines of sight. Many offices and car parks use some RFID based solutions to allow the access for authorized people only. Recently, RFID technology has been used to implement fast and secure payment services, using disposable wristbands that stop functioning once removed from the wrist and cannot be put back together.

Nowadays, also the healthcare world is rapidly approaching to RFID, both for increasing the automation level and for reducing the overall clinical risk for patients. Following, are few examples.

Passive RFID tags are used on surgical tools to read the composition of a sterile surgical kit prior to start the operation.

RFID wristbands can be worn by patients for reducing identification errors and for tracking their therapies or treatments. If the wristbands are equipped with active RFID tags, the patient position inside the hospital can also be easily monitored and tracked: this is particularly useful to caregivers for managing children or patients with reduced cognitive functions.

Blood transfusion errors can be heavily reduced by using RFID in the blood supply chain: patients and bags of blood can be tagged to make sure every patient receives the right blood product.

Similarly, the pharmaceutical supply chain could take advantage of RFID technology both for replacing barcodes and for implementing single-dose delivery automated systems [9].

An RFID system is typically composed by at least two components: tag and reader. In the simplest functioning mode, when the reader "wakes up" the tag (forward link), this responds by transmitting its own unique ID code (reverse link). If the tag is passive, i.e. is not provided with a battery power, the reader itself must energize the tag. The communication between the reader and the tag can hence be only initiated by the reader (Figure 1).

\section{Results}

We started the design process by spotting 28 requirements to which our device must respond (see Table 1) and generating 20 corresponding technical specifications (see Table 2). The identified requirements relate to aspects of process safety as well as to procedural aspects and usability. Also affordability is an issue, to guarantee the widest dissemination of our device in hospitals.

The device, based on above requirements and technical specifications, is a container with an electronically operated lock that opens only when the opening attempt is performed by the patient to whom the drugs are destined (or by healthcare staff), thus dramatically reducing the chance of wrong administrations. The device integrates a custom miniaturized RFID reader operating at $13.56 \mathrm{MHz}$ for the recognition of the patient and/or operator that must wear a simple and cheap passive ISO 15693 compatible wrist band. The compliancy to this standard guarantees maximum compatibility to bracelets commercially available.

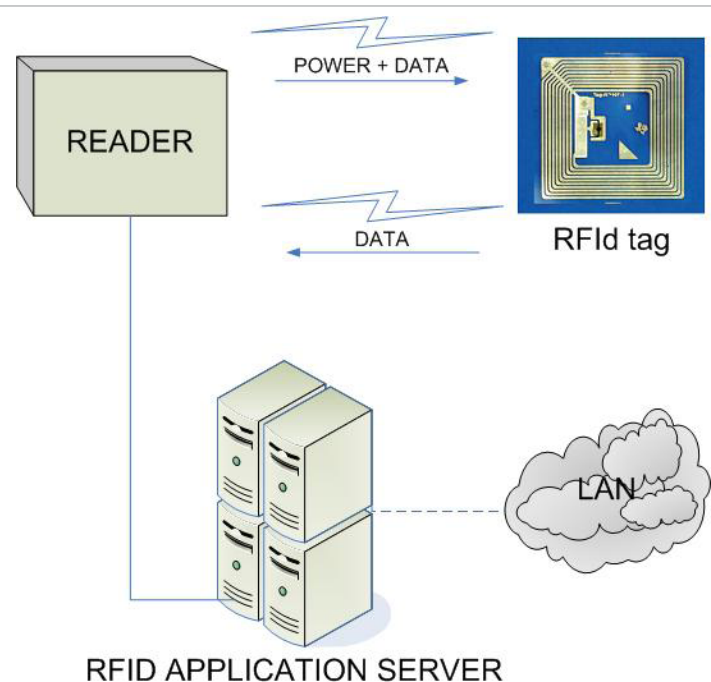

Figure 1: A simple RFID system.

\begin{tabular}{|c|c|c|}
\hline Code & Requirement & $\begin{array}{l}\text { Technical } \\
\text { specifications }\end{array}$ \\
\hline R.1 & Integration with Hospital Information System & S.1 \\
\hline R.2 & Small reading distance between tags and device & S.2 \\
\hline R.3 & $\begin{array}{l}\text { Each patient must be provided with an } \\
\text { identification device }\end{array}$ & S.3 \\
\hline R.4 & $\begin{array}{l}\text { The container of drugs should prevent } \\
\text { unauthorized openings }\end{array}$ & S.4 \\
\hline R.5 & Tags collision management & S.5 \\
\hline R.6 & Wearable identification device & S.3 \\
\hline R.7 & ID device hygienic & S.3 \\
\hline R.8 & Drugs container sanitisable & S.6 \\
\hline R.9 & $\begin{array}{l}\text { Drugs container must protect drugs from direct } \\
\text { lightening }\end{array}$ & S.7 \\
\hline R.10 & Drugs temperature must never exceed $30^{\circ} \mathrm{C}$ & S.8 \\
\hline R.11 & Water-proof drugs container & S.9 \\
\hline R.12 & Access to medications must be controllable & S.2,S.3,S.4,S.10 \\
\hline R.13 & $\begin{array}{l}\text { Tracking of every attempt (successful or not) to } \\
\text { access drugs }\end{array}$ & S.5,S.11 \\
\hline R.14 & ID device not expensive & S.3 \\
\hline R.15 & Drugs container ergonomic & S.12 \\
\hline R.16 & $\begin{array}{l}\text { Drugs container big enough to contain a whole } \\
\text { medication therapy }\end{array}$ & S.19 \\
\hline R.17 & Procedure for drugs distribution & S.1 \\
\hline R.18 & Procedure for drugs administration & S.2,S.3,S.10 \\
\hline R.19 & $\begin{array}{l}\text { Information to patients about the use of the } \\
\text { device }\end{array}$ & S.13 \\
\hline R.20 & Low power consumption & S.20 \\
\hline R.21 & $\begin{array}{l}\text { Staff must be able to force the device opening in } \\
\text { case of emergency }\end{array}$ & S.14 \\
\hline R.22 & Emergency openings must be logged & S.11 \\
\hline R.23 & $\begin{array}{l}\text { Easy identification of the association patient- } \\
\text { container }\end{array}$ & S.15 \\
\hline R.24 & Reprogrammable & S.2,S.16 \\
\hline R.25 & Faults management & S.5 \\
\hline R.26 & $\begin{array}{l}\text { Verification of the right association between } \\
\text { patient and medication }\end{array}$ & S.4,S.5,S.17 \\
\hline R.27 & $\begin{array}{l}\text { Alarm in case of wrong association between } \\
\text { patient and medication }\end{array}$ & S.4,S.5,S.17 \\
\hline R.28 & Controlled administration & S.18 \\
\hline
\end{tabular}

Table 1: Requirements and corresponding technical specifications. 


\begin{tabular}{|c|c|c|}
\hline Code & Technical specification & Type \\
\hline S.1 & Electronic Patient Records + CPOE + smart cabinets for a global automated management of drugs distribution system & Software, electronic \\
\hline S.2 & RFID reader and RFID tag following ISO15693 standard & Electronic, technological \\
\hline S.3 & Disposable wristband RFID tag & Technological \\
\hline S.4 & Electro-mechanic cover control & Electro-mechanic \\
\hline S.5 & Warning system using LED lighting & Electronic \\
\hline S.6 & Sanitized container with the possibility of putting disposable bags inside & Mechanic \\
\hline S.7 & Semi-transparent container & Mechanic \\
\hline S.8 & Screen insulation between the electronics section of the container and drug section & Mechanic \\
\hline S.9 & Degree of protection IP47 & Mechanic \\
\hline S.10 & Unambiguous association between the container and patient medication & Electronic, Firmware \\
\hline S.11 & Internal memory for access logging & Electronic \\
\hline S.12 & Cylindrical shape of small dimensions in the central part of the body & Mechanic \\
\hline S.13 & Short training course on the use of the device to the medical staff & Methodological \\
\hline S.14 & Master key tags & Technological \\
\hline S.15 & LCD character display & Methodological \\
\hline S.16 & RFID reader with a microprocessor system equipped with a PC interface for manual or automatic programming & Software, Technological \\
\hline S.17 & Opening the cover by pressing the release button & Electro-mechanic \\
\hline S.18 & Record of device opening and closing on internal memory & Software \\
\hline S.19 & Dimensions of the container equal to $8 \mathrm{~cm}$ in diameter and $11 \mathrm{~cm}$ in height & Methodological \\
\hline S.20 & Adequate battery life & Electronic \\
\hline
\end{tabular}

Table 2: Technical specifications.

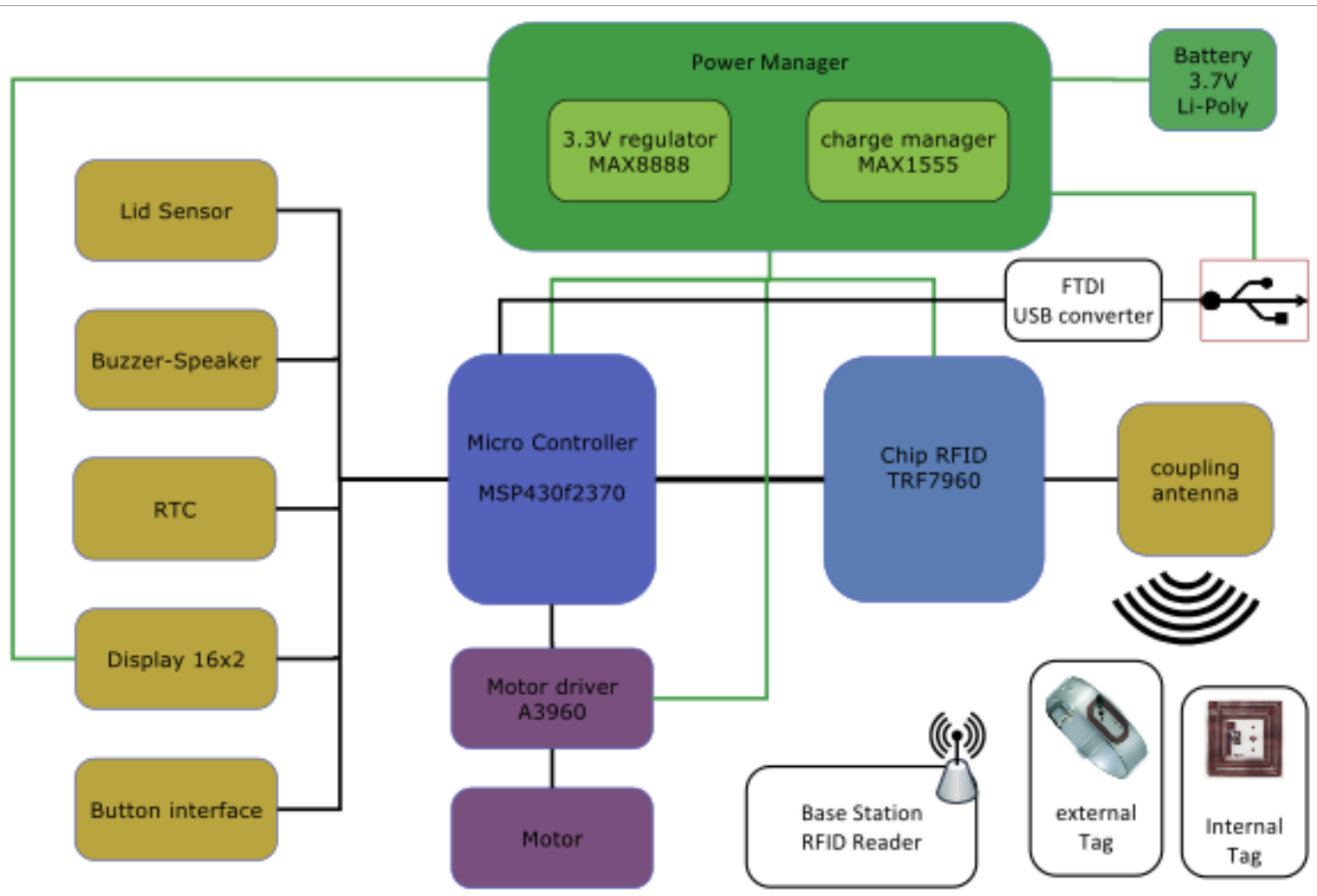

Figure 2: Block diagram of the device components

As shown in figure 2, the device incorporates an internal tag that will contain information about the patient's identity and his drug therapy. This solution has been preferred to flash memories because in this way we can read/write on this "internal memory" using the onboard electronic card or a standard external RFID reader without any wired connections. Each attempt to open the device (successful or not) and each consequent alarm is logged using this internal tag as an on-board memory. The device is also provided with an USB port, but this is used just for battery recharge and for firmware maintenance.

As stated in specification S.5 (see Table 2), the container is provided with two LEDs, a red one and a green one, to give feedback to the user about the correct patient-drugs matching.

The technical specification S.15 is satisfied by providing a small 16 

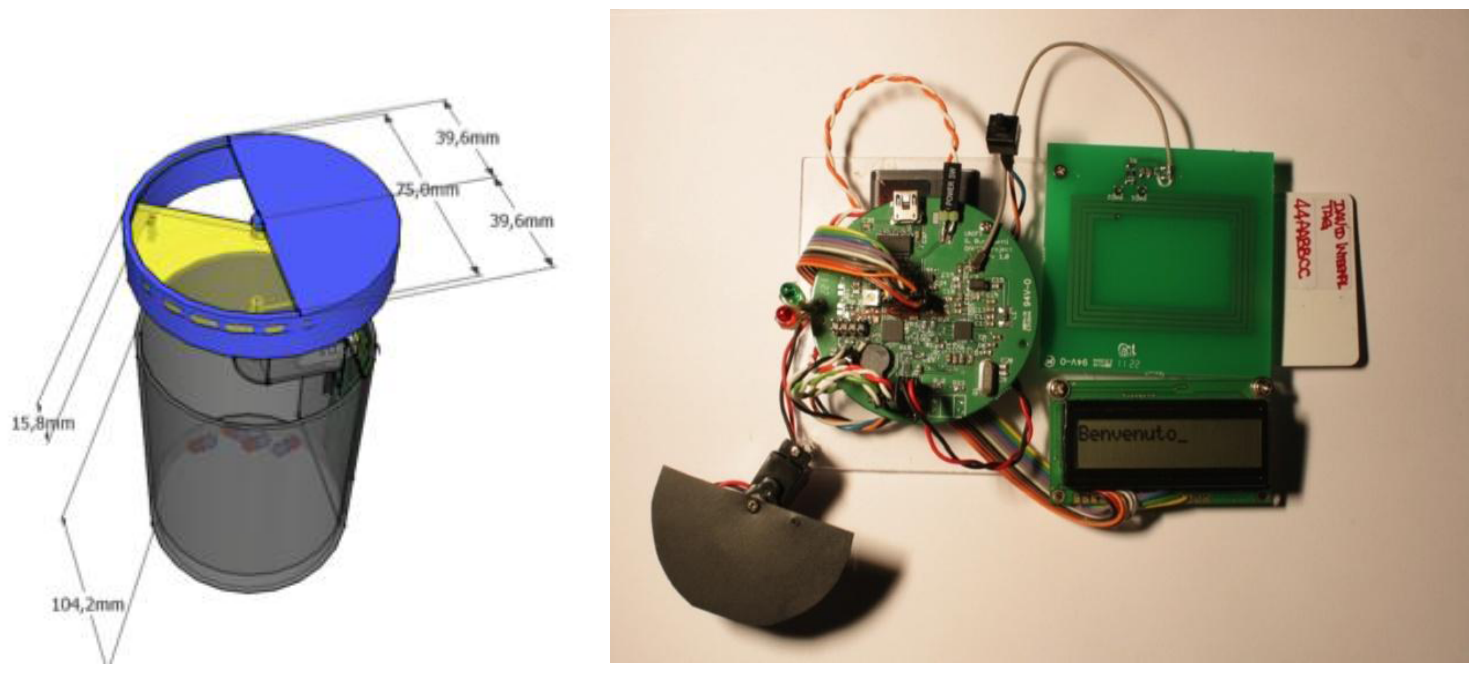

Figure 3: The RFID drug container.

$\times 2$ display. This is used to show the name of the patient for which the device has been prepared for, and to display the list of drugs prescribed to the patient.

The firmware is also able to read the drugs inserted into the device (provided that they are tagged with RFID) and to prevent its opening if some un-prescribed drug is found inside the container, alerting the patient/operator using the on-board display (Figure 3).

A functioning stand-alone prototype device has been realized and tested. It still lacks a mechanical prototype.

\section{Discussion}

The patient himself can easily operate the presented device, since its input interface consists of a single button, to be pressed after placing the device in proximity of the RFID wristband. It is also possible, for caregivers, to force the opening by using their own RFID badge. All these operations are logged in the internal tag and can be wirelessly sent to a central HIS (Hospital Information System).

By logging the number of granted/denied openings, the device could feed a Hospital Risk Management System, providing the risk manager with some valuable data to assess the quality of the medication service. If inserted in a CEP (Complex Event Processing) system the proposed device could significantly increase the patient's safety as well as the knowledge of the process by the hospital executives.

The ideal usage scenario provides an interface between the device and the hospital information system and $\mathrm{CPOE}$ and with an automated pharmacy that provides single dose RFID-tagged medications. In this setting, the device can easily signal mistakes in the preparation before the wrong drugs can reach the patient. It will also prevent openings in this case.

Future works include improving the performance of the antenna, realizing a mechanical prototype and analysing the domestic scenario for possible use of the device at home.

\section{Acknowledgement}

Author thanks Lorenzo Baroncelli, Aldo Manetti and Giovanni Burchietti for the big effort profused in this project. Heartfelt thanks goes to prof. Biffi for the expert help.

\section{References}

1. http://www.fda.gov/drugs/drugsafety/medicationerrors/default.htm

2. Nebeker JR, Barach P, Samore M H (2004) Clarifying adverse drug events: A clinician's guide to terminology, documentation, and reporting. Ann Intern Med 140: 795-801.

3. Hartwig SC, Denger S D, Schneider PJ (1991) Severity-indexed, incident report-based medication error-reporting program. Am J Hosp Pharm 48: 2611 2616

4. Bates DW, Cullen DJ, Laird N, Petersen LA, Small SD, et al. (1995) Incidence of adverse drug events and potential adverse drug events. Implications for prevention. ADE Prevention Study Group. JAMA 274: 29-34.

5. Johnson VR, Hummel J, Kinninger T, Lewis RR (2004) Immediate steps toward patient safety. Healthc Financ Manage 58: 56-61.

6. Perrin RA, Simpson N (2004) RFID and bar codes--critical importance in enhancing safe patient care. J Healthc Inf Manag 18: 33-39.

7. Iadanza E, Dori F, Miniati R, Bonaiuti R (2008) Patients tracking and identifying inside hospital: A multilayer method to plan an RFId solution. 30th Annual International Conference of the IEEE Engineering in Medicine and Biology Society, EMBS'08, Italy.

8. BiffiGentili G, Dori F, ladanza E (2010) Dual-frequency active RFID solution for tracking patients in a children's hospital. Design method, test procedure, risk analysis, and technical solution. Proceedings of the IEEE 98: 1656-1662.

9. Iadanza Ernesto (2009) Recent Advances in Biomedical Engineering, InTech Croatia 